Article

\title{
Exploitation of Three Non-Conventional Yeast Species in the Brewing Process
}

\author{
Laura Canonico ${ }^{1}$, Edoardo Galli ${ }^{1}$, Enrico Ciani ${ }^{2}$, Francesca Comitini ${ }^{1}$ and Maurizio Ciani ${ }^{1, *}$ (D) \\ 1 Dipartimento Scienze della Vita e dell'Ambiente, Università Politecnica delle Marche, Via Brecce Bianche, \\ 60131 Ancona, Italy; l.canonico@univpm.it (L.C.); edogah@hotmail.it (E.G.); f.comitini@univpm.it (F.C.) \\ 2 Birra dell'Eremo, microbrewery, Via Monte Peglia, 5, 06081 Assisi, Italy; enrico@birradelleremo.it \\ * Correspondence: m.ciani@univpm.it; Tel.: +39-071-220-4987
}

Received: 3 December 2018; Accepted: 2 January 2019; Published: 8 January 2019

\begin{abstract}
Consumers require high-quality beers with specific enhanced flavor profiles and non-conventional yeasts could represent a large source of bioflavoring diversity to obtain new beer styles. In this work, we investigated the use of three different non-conventional yeasts belonging to Lachancea thermotolerans, Wickerhamomyces anomalus, and Zygotorulaspora florentina species in pure and mixed fermentation with the Saccharomyces cerevisiae commercial starter US-05. All three non-conventional yeasts were competitive in co-cultures with the $S$. cerevisiae, and they dominated fermentations with 1:20 ratio (S. cerevisiae/non-conventional yeasts ratios). Pure non-conventional yeasts and co-cultures affected significantly the beer aroma. A general reduction in acetaldehyde content in all mixed fermentations was found. L. thermotolerans and Z. florentina in mixed and W. anomalus in pure cultures increased higher alcohols. L. thermotolerans led to a large reduction in $\mathrm{pH}$ value, producing, in pure culture, a large amount of lactic acid $(1.83 \mathrm{~g} / \mathrm{L})$ while showing an enhancement of ethyl butyrate and ethyl acetate in all pure and mixed fermentations. W. anomalus decreased the main aroma compounds in comparison with the $S$. cerevisiae but showed a significant increase in ethyl butyrate and ethyl acetate. Beers produced with Z. florentina were characterized by an increase in the isoamyl acetate and $\alpha$-terpineol content.
\end{abstract}

Keywords: non-conventional yeasts; yeast interactions; beer; bioflavor

\section{Introduction}

In the brewing industry, Saccharomyces cerevisiae and Saccharomyces pastorianus are the most used yeast species in starter cultures ensuring certain advantages in the fermentation process and in the standard product quality. In the past few years, brewers have payed attention to yeast selection not only for their fermentation efficiency and technological advantages but also for the aromatic characters and the flavors they give to the final product. To this end, recent genetic investigations have focused on methods to enhance the fermentation efficiency and aromatic profile of selected S. cerevisiae strains [1-3]. Other studies proposed the isolation of new starter yeasts (S. cerevisiae) from natural matrices [4,5] and the selection of wine yeast strains [6]. In recent years, the rapid expansion in the number of microbreweries has led the brewers to differentiate their products through the use of alternative raw materials and the selection and use of non-conventional yeasts [7-10]. Indeed, bioflavor from metabolic pathways of yeasts may be a suitable strategy to obtain beer with a different aromatic taste [11,12]. In this context, the use of non-conventional yeasts could be an alternative way to enhance the aroma profile of beers. Within non-conventional yeasts, different genera and species have been proposed. Torulaspora delbrueckii is a yeast species widely studied in winemaking for its ability to produce fruitiness and positive aromatic flavor, and for this reason, it was also evaluated for beer production, both in pure and in mixed cultures with different $S$. cerevisiae starter strains $[7,13]$. Beers 
produced with pure cultures of $T$. delbrueckii were characterized by a low alcohol content $(2.66 \% v / v)$ but at the same time with distinctive analytical and aromatic profile [7,14]. Lachancea termotholerans, another non-conventional yeast species, was proposed by Domizio et al. [15] to produce sour beers without the use of lactic acid bacteria. Indeed, they investigated the use of a strain of $L$. thermotolerans in pure culture able to decrease the $\mathrm{pH}$ value and increase the glycerol and lactic acid production. Other non-conventional yeasts belonging to the Hanseniaspora vineae, Lachancea fermentati, Schizosaccharomyces japonicus, and Wickerhamomyces anomalus species showed promising fermentation aptitude and sensory features for the production of sour beer [8]. In addition, yeasts belonging to Cyberlindnera fabianii, Pichia kudriavzevii, and Pichia kluyverii were evaluated to tailor the aroma production and the ethanol content in beer $[16,17]$.

In the present study, after a preliminary screening of yeasts from the Collection of the Department of Life and Environmental Sciences (DiSVA), we evaluated the use of selected strains of L. thermotolerans, W. anomalus, and Zygotorulaspora florentina in pure and in mixed fermentation at different inoculation ratios with $S$. cerevisiae in the brewing process. The yeast strains' population dynamic and their influence on the bioflavor of beer were evaluated.

\section{Materials and Methods}

\subsection{Yeast Strains}

The yeast strains used in this study were six strains of $L$. thermotolerans, nine strains of $W$. anomalus and eight strains of Z. florentina coming from the Yeast Collection of (DiSVA) of the Polytechnic University of Marche (Italy). The S. cerevisiae commercial strain US-05 (Fermentis, Lesaffre, France) was used in the mixed fermentation trials and as the control. The US-05 was rehydrated following the manufacturer's instructions.

\subsection{Preliminary Screening and Fermentation Trials}

The fermentation of maltose by these non-conventional yeasts strains was assessed in flasks containing $100 \mathrm{~mL}$ of malt extract $10 \%$. The capacity to utilise the maltose was determined by measuring the weight loss of the flasks due to the $\mathrm{CO}_{2}$ evolution, which was followed to the end of the fermentation (i.e., constant weighing for 3 consecutive days). From this preliminary screening, the strains able to ferment maltose were selected and used in pure and mixed fermentations with the S. cerevisiae US-05 starter strain at different ratios of S. cerevisiae to non-Saccharomyces (i.e., 1:1, 1:10, 1:20). The fermentation performances of the strains in pure and mixed fermentations were evaluated in 500-mL flasks containing $500 \mathrm{~mL}$ of wort at $19 \pm 1{ }^{\circ} \mathrm{C}$ and inoculated by pre-cultures grown in $10 \%$ malt extract at $19 \pm 1{ }^{\circ} \mathrm{C}$ for $48 \mathrm{~h}$, locked with a Müller valve containing sulphuric acid, to allow the $\mathrm{CO}_{2}$ to escape from the system in the same conditions reported by Canonico et al. [7,13].

The populations dynamic was monitored during the fermentation process collecting the samples at established intervals. One hundred $\mu \mathrm{L}$ aliquots of serial dilutions of each sample were plated onto both WL nutrient Agar (Oxoid, Hampshire, UK) and Lysine Agar (Oxoid, Hampshire, UK) able to differentiate non-Saccharomyces yeast population from the US-05 S. cerevisiae starter strain as reported by Canonico et al. $[7,13]$. The fermentations were carried out in triplicate trials under static conditions.

\subsection{Wort Production}

The wort used for the micro fermentation trials was made with $100 \%$ pilsner malt and the Cascade hop variety by Birra dell'Eremo Microbrewery (Assisi, Italy). The wort was produced from a batch of $1500 \mathrm{~L}$ following these mashing steps: $53^{\circ} \mathrm{C}$ for $10 \mathrm{~min}, 67^{\circ} \mathrm{C}$ for $70 \mathrm{~min}$, and $76{ }^{\circ} \mathrm{C}$ for $10 \mathrm{~min}$, with boiling for $60 \mathrm{~min}$. The wort obtained showed the following main analytical characters: $\mathrm{pH}$ 5.47; specific gravity $12.3^{\circ}$ Plato (original gravity of 1.050); free assimilable nitrogen, $263 \mathrm{mg} \mathrm{N} / \mathrm{L}$, and 20 IBU (International Bitterness Unit). 


\subsection{Analytical Procedures}

The Official European Union Methods [18] were used to determine the ethanol content, volatile acidity, and $\mathrm{pH}$. Acetaldehyde, ethyl acetate, n-propanol, isobutanol, amyl, and isoamyl alcohols, and acetoin were quantified by direct injection into a gas-liquid chromatography system (GC-2014; Shimadzu, Kjoto, Japan). Each sample was prepared and analysed as reported by Canonico et al. [19].

The solid-phase microextraction (HS-SPME) method was used to determine the concentration of the volatile compounds. Five $\mathrm{mL}$ of beer was placed in a vial containing $1 \mathrm{~g} \mathrm{NaCl}$ closed with a septum-type cap. HS-SPME was carried out with magnetic stirring for $10 \mathrm{~min}$ at $25{ }^{\circ} \mathrm{C}$. After this period, the internal standard (3-octanol) at a concentration of $1.6 \mathrm{mg} / \mathrm{L}$ was added, and the sample was heated to $40^{\circ} \mathrm{C}$. Divinylbenzene/carboxen/polydimethylsiloxane (DVB/CAR/PDMS) fibre (Sigma-Aldrich) was inserted into the vial headspace for $30 \mathrm{~min}$. The compounds were desorbed by inserting the fibre into a Shimadzu gas chromatograph GC injector for $5 \mathrm{~min}$. A glass capillary column was used: $0.25 \mu \mathrm{m}$ Supelcowax 10 (length, $60 \mathrm{~m}$; internal diameter, $0.32 \mathrm{~mm}$ ). The fibre was inserted in the split-splitless mode as reported by Canonico et al. [19]. The compounds were identified and quantified by comparisons with external calibration curves for each compound.

Final gravity was determined by a densimeter (Polsinelli Enologia Srl, Isola Liri, Italy) at a temperature of $20^{\circ} \mathrm{C}$. Specific enzymatic kit (Megazyme, Wicklow, Ireland) was used to determine the concentration of lactic acid (kit K-DLATE) according to the manufacturer instructions.

\subsection{Statistical Analysis}

Analysis of variance (ANOVA) was applied to the experimental data for the main characteristics of the beers. The means were analysed using STATISTICA 7 software. Significant differences were determined by the means of Duncan tests, and the results were considered significant if the associated $p$ values were $<0.05$. Principal component analysis (PCA) was applied to discriminate between the means of the contents of esters, higher alcohols, and carbonyl compounds in the beers from the pure and mixed fermentations PCA, which was carried out using the statistical software package JMP $11^{\circledR}$. The mean data were normalised to neutralize any influence from hidden factors. The PCA provides a graphical representation of the overall differences due to the non-Saccharomyces in terms of fermenting products of the final beers.

\section{Results}

\subsection{Preliminary Screening}

Initial screening of the strains belonging to the different species was carried out to determine their ability to ferment maltose, the most abundant fermentable sugar in the brewing wort, to select for their potential use in beer production (Table 1). The results of the fermentation capacity showed that all of the strains tested exhibited the ability to ferment maltose, although even at different grades. From the strains tested, we chose L. thermotolerans DISVA 322, Z. florentina, DiSVA 263, and W. anomalus DiSVA 2 since they showed the best fermentative performance with the highest final $\mathrm{CO}_{2}$ evolved. Regarding the species W. anomalus, the data reported in Table 1 highlighted that different strains belonging to this species exhibited a good fermentation performance. The choice to select $W$. anomalus DiSVA 2 has been evaluated taking into account the screening and the results reported by Oro et.al [20] regarding the metabolic activities and aromatic compounds production. For these reasons, these three strains were selected for the subsequent micro-fermentation trials in pure and in co-culture at different inoculation ratios S. cerevisiae/non-conventional yeasts $(1: 1 ; 1: 10 ; 1: 20)$ using the $S$. cerevisiae starter strain US-05. 
Table 1. Fermentation parameters of different non-conventional yeasts on malt extract.

\begin{tabular}{|c|c|c|}
\hline Strains & $\begin{array}{c}\text { Total } \mathrm{CO}_{2} \mathrm{~g} \text { Evolved } \\
\text { (20 Days) }\end{array}$ & $\begin{array}{l}\text { Fermentation Rate } \\
\left(\mathrm{g} \mathrm{CO}_{2} / \text { Day }\right)\end{array}$ \\
\hline L. thermotolerans DiSVA 322 & $3.87 \pm 0.05$ & $0.31 \pm 0.05$ \\
\hline L. thermotolerans DISVA 324 & $3.49 \pm 0.04$ & $0.16 \pm 0.03$ \\
\hline L. thermotolerans DiSVA 325 & $2.04 \pm 0.37$ & $0.13 \pm 0.06$ \\
\hline L. thermotolerans DiSVA 326 & $2.13 \pm 0.20$ & $0.10 \pm 0.05$ \\
\hline L. thermotolerans DiSVA 327 & $3.60 \pm 0.08$ & $0.16 \pm 0.05$ \\
\hline W. anomalus DiSVA 2 & $1.68 \pm 0.40$ & $0.22 \pm 0.09$ \\
\hline W. anomalus DiSVA 45 & $1.30 \pm 0.21$ & $0.17 \pm 0.06$ \\
\hline W. anomalus DiSVA 45 & $1.84 \pm 0.12$ & $0.23 \pm 0.07$ \\
\hline W. anomalus DiSVA 56 & $1.58 \pm 0.06$ & $0.16 \pm 0.03$ \\
\hline W. anomalus DiSVA 336 & $1.27 \pm 0.03$ & $0.18 \pm 0.03$ \\
\hline W. anomalus DiSVA 355 & $1.47 \pm 0.12$ & $0.19 \pm 0.04$ \\
\hline W. anomalus DiSVA 356 & $1.58 \pm 0.35$ & $0.21 \pm 0.10$ \\
\hline W. anomalus DiSVA 359 & $1.40 \pm 0.25$ & $0.18 \pm 0.02$ \\
\hline W. anomalus DiSVA 383 & $1.69 \pm 0.07$ & $0.22 \pm 0.05$ \\
\hline W. anomalus DiSVA 384 & $1.45 \pm 0.09$ & $0.20 \pm 0.06$ \\
\hline W. anomalus DiSVA 385 & $1.71 \pm 0.14$ & $0.20 \pm 0.06$ \\
\hline W. anomalus DiSVA 386 & $1.82 \pm 0.11$ & $0.23 \pm 0.06$ \\
\hline Z. florentina DiSVA 262 & $3.41 \pm 0.12$ & $0.34 \pm 0.02$ \\
\hline Z. florentina DiSVA 263 & $3.66 \pm 0.13$ & $0.32 \pm 0.06$ \\
\hline Z. florentina DiSVA 264 & $2.33 \pm 0.14$ & $0.14 \pm 0.03$ \\
\hline Z. florentina DiSVA 309 & $2.52 \pm 0.21$ & $0.23 \pm 0.05$ \\
\hline Z. florentina DiSVA 310 & $1.14 \pm 0.36$ & $0.16 \pm 0.05$ \\
\hline Z. florentina DiSVA 311 & $1.16 \pm 0.09$ & $0.23 \pm 0.09$ \\
\hline Z. florentina DiSVA 312 & $1.84 \pm 0.14$ & $0.27 \pm 0.07$ \\
\hline Z. florentina DiSVA 317 & $0.68 \pm 0.31$ & $0.01 \pm 0.01$ \\
\hline S. cerevisae US-05 & $4.61 \pm 0.05$ & $0.65 \pm 0.04$ \\
\hline
\end{tabular}

Data are the means \pm standard deviations. $\mathrm{CO}_{2} \mathrm{~g}$ evolved after 20 days of fermentation (in $100 \mathrm{~mL}$ of $10 \%$ malt extract). Fermentation rate: $\mathrm{CO}_{2} \mathrm{~g} /$ day (over the first 6 days of fermentation).

\subsection{Fermentation Trials with the Selected Non-Saccharomyces Yeasts}

\subsubsection{Evaluation of Population Dynamics}

The growth kinetics of L. thermotolerans in pure and in mixed fermentation are reported in Figure 1. The S. cerevisiae US-05 pure cultures achieved $10^{8} \mathrm{CFU} / \mathrm{mL}$ after four days of fermentation (maximum viable cells) and maintained $10^{7} \mathrm{CFU} / \mathrm{mL}$ until the end of the fermentation. Differently, in the mixed cultures with the inoculation ratio of 1:1 (Figure 1a), S. cerevisiae US-05 reached a lower biomass, achieving only $10^{7} \mathrm{CFU} / \mathrm{mL}$ on the fourth day of fermentation. The same trend was also exhibited for S. cerevisiae US-05 with the inoculation ratios of 1:10 and 1:20 (Figure 1b,c). S. cerevisiae was not inhibited at all in the inoculation ratios and completed fermentation as showed by residual sugar and ethanol content in the final beers (Table 2).

L. thermotolerans in mixed fermentation at the 1:10 and 1:20 inoculation ratios showed a biomass evolution comparable with that of the pure culture, while at the 1:1 inoculation ratio, L. thermotolerans showed a very limited increase in biomass compared with that exhibited by S. cerevisiae under the same conditions (Figure 1a). Under these conditions, both strains suffered a mutual inhibition but showed no differences compared with the control trial (US 05 strain) (Table 2).

The biomass evolution of the $S$. cerevisiae and Z. florentina mixed fermentations at the 1:1 inoculation ratio (Figure 2a) exhibited a similar growth kinetic (with a slight prevalence of S. cerevisiae), and they reached a maximum cell concentration of $10^{7} \mathrm{~mL} / \mathrm{L}$ after four days, showing a reciprocal inhibition compared with pure cultures. 


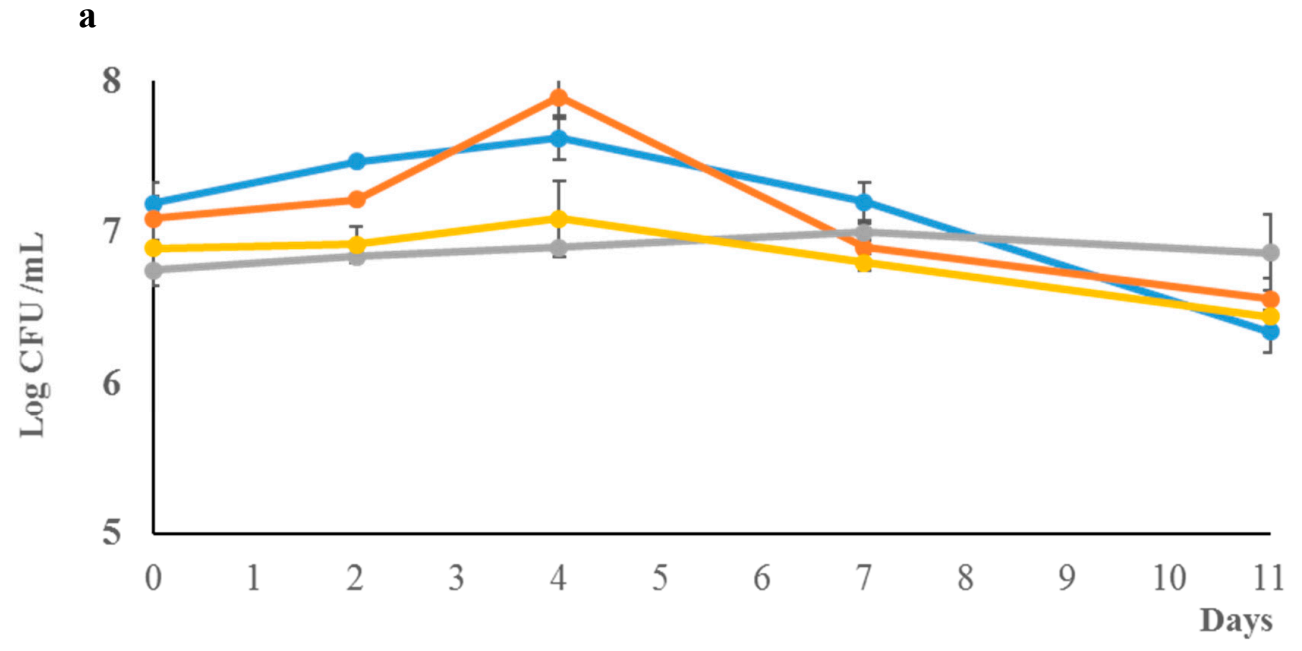

b

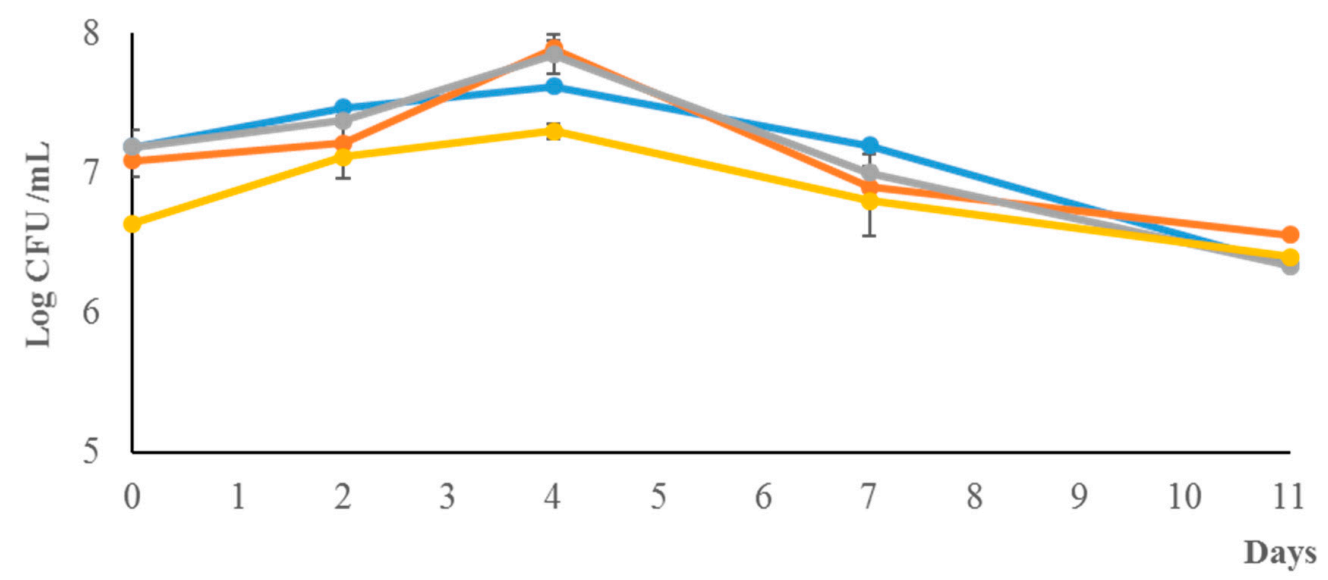

c

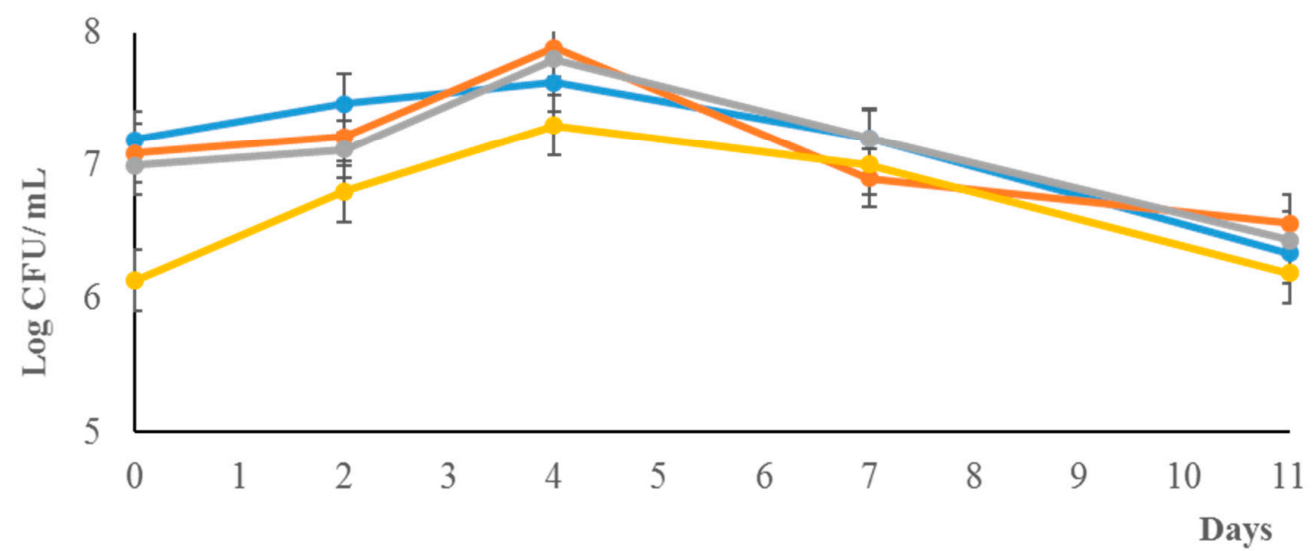

Figure 1. Growth kinetics of L. thermotolerans in pure and mixed fermentation. Pure cultures of $L$. thermotolerans $(\rightarrow)$ and S. cerevisiae $(-)$ ) and for the mixed fermentations with S. cerevisiae $(-\infty)$ and L. thermotolerans (-) individually in the mixed cultures at 1:1 (a), 1:10 (b) and 1:20 (c). 
Table 2. The main analytical characteristics of the beer produced by the pure and mixed fermentations.

\begin{tabular}{|c|c|c|c|c|c|c|c|c|}
\hline Fermentation & Ethanol $(\% v / v)$ & $\begin{array}{c}\text { Residual Sugar } \\
\text { g/L (Maltose) }\end{array}$ & Final Gravity & $\begin{array}{c}\text { Apparent } \\
\text { Attenuation (\%) }\end{array}$ & $\begin{array}{c}\text { Real Attenuation } \\
(\%)\end{array}$ & $\begin{array}{c}\text { Volatile Acidity } \\
(\mathrm{g} / \mathrm{L})\end{array}$ & $\mathrm{pH}$ & $\begin{array}{c}\text { Lactic Acid } \\
(\mathrm{g} / \mathrm{L})\end{array}$ \\
\hline L. thermotolerans DiSVA 322 & $3.12 \pm 0.32^{b}$ & $12.32 \pm 0.03^{\mathrm{a}}$ & $1.023 \pm 0.17^{\mathrm{b}}$ & $48.95 \pm 1.47^{\mathrm{c}}$ & $39.80 \pm 1.20^{\mathrm{c}}$ & $0.38 \pm 0.00^{\mathrm{a}}$ & $3.88 \pm 0.03^{b}$ & $1.83 \pm 0.07^{\mathrm{a}}$ \\
\hline 0.0US05 + DiSVA 322 1:1 & $4.03 \pm 0.01^{\mathrm{a}}$ & $0.07 \pm 0.03^{b}$ & $1.015 \pm 0.0^{c}$ & $68.75 \pm 0.00^{\mathrm{b}}$ & $55.90 \pm 0.00^{\mathrm{b}}$ & $0.34 \pm 0.00^{\mathrm{a}}$ & $4.23 \pm 0.18^{\mathrm{a}}$ & $0.53 \pm 0.05^{c}$ \\
\hline US05 + DiSVA 322 1:20 & $4.09 \pm 0.23^{\mathrm{a}}$ & $0.02 \pm 0.04^{b}$ & $1.015 \pm 0.00^{\mathrm{c}}$ & $68.75 \pm 0.02^{b}$ & $55.90 \pm 0.00^{\mathrm{b}}$ & $0.36 \pm 0.16^{\mathrm{a}}$ & $4.14 \pm 0.00^{\mathrm{a}}$ & $0.85 \pm 0.04^{b}$ \\
\hline S. cerevisiae US05 & $4.03 \pm 0.11^{\mathrm{a}}$ & $0.05 \pm 0.01^{b}$ & $1.010 \pm 0.00^{\mathrm{a}}$ & $79.16 \pm 0.00^{a}$ & $64.36 \pm 0.00^{a}$ & $0.36 \pm 0.00^{\mathrm{a}}$ & $4.46 \pm 0.12^{\mathrm{a}}$ & $0.01 \pm 0.00^{\mathrm{d}}$ \\
\hline Z. florentina DiSVA 263 & $3.47 \pm 0.15^{b}$ & $17.32 \pm 0.10^{\mathrm{a}}$ & $1.025 \pm 0.00^{\mathrm{b}}$ & $47.91 \pm 2.94^{\mathrm{d}}$ & $38.95 \pm 2.40^{\mathrm{d}}$ & $0.34 \pm 0.00^{\mathrm{b}}$ & $4.48 \pm 0.02^{\mathrm{a}}$ & $0.21 \pm 0.05^{\mathrm{a}}$ \\
\hline US05 + DiSVA 263 1:10 & $3.81 \pm 0.07^{b}$ & $0.32 \pm 0.01^{b}$ & $1.020 \pm 0.00^{c}$ & $58.33 \pm 0.00^{c}$ & $47.42 \pm 0.00^{c}$ & $0.38 \pm 0.00^{b}$ & $4.53 \pm 0.26^{\mathrm{a}}$ & $0.05 \pm 0.02^{b}$ \\
\hline US05 + DiSVA 263 1:20 & $4.30 \pm 0.07^{\mathrm{a}}$ & $0.02 \pm 0.01^{b}$ & $1.015 \pm 0.17^{\mathrm{d}}$ & $68.75 \pm 2.94^{\mathrm{b}}$ & $55.89 \pm 2.40^{\mathrm{b}}$ & $0.60 \pm 0.00^{\mathrm{a}}$ & $4.42 \pm 0.16^{\mathrm{a}}$ & $0.16 \pm 0.01^{\mathrm{a}}$ \\
\hline S. cerevisiae US05 & $4.03 \pm 0.11^{\mathrm{a}}$ & $0.05 \pm 0.01^{b}$ & $1.010 \pm 0.00^{\mathrm{a}}$ & $79.16 \pm 0.00^{a}$ & $64.36 \pm 0.00^{\mathrm{a}}$ & $0.36 \pm 0.00^{b}$ & $4.46 \pm 0.12^{\mathrm{a}}$ & $0.01 \pm 0.00^{\mathrm{b}}$ \\
\hline W. anomalus DiSVA 2 & $1.53 \pm 0.10^{\mathrm{b}}$ & $57.32 \pm 0.05^{\mathrm{a}}$ & $1.035 \pm 0.00^{\mathrm{a}}$ & $27.08 \pm 2.94^{c}$ & $22.02 \pm 2.39^{c}$ & $0.46 \pm 0.00^{\mathrm{a}}$ & $4.75 \pm 0.02^{\mathrm{a}}$ & $0.17 \pm 0.01^{\mathrm{a}}$ \\
\hline US05 + DiSVA 2 1:1 & $4.06 \pm 0.01^{\mathrm{a}}$ & $0.07 \pm 0.01^{b}$ & $1.015 \pm 0.00^{\mathrm{b}}$ & $69.79 \pm 0.00^{\mathrm{b}}$ & $55.89 \pm 0.00^{b}$ & $0.22 \pm 0.00^{c}$ & $4.48 \pm 0.11^{\mathrm{a}}$ & $0.12 \pm 0.01^{b}$ \\
\hline US05 + DiSVA 2 1:10 & $4.01 \pm 0.04^{\mathrm{a}}$ & $0.02 \pm 0.01^{b}$ & $1.015 \pm 0.17^{\mathrm{b}}$ & $55.89 \pm 2.94^{b}$ & $56.74 \pm 2.39^{b}$ & $0.34 \pm 0.00^{b}$ & $4.44 \pm 0.21^{\mathrm{a}}$ & $0.19 \pm 0.00^{\mathrm{a}}$ \\
\hline US05 + DiSVA 2 1:20 & $3.99 \pm 0.47^{\mathrm{a}}$ & $0.02 \pm 0.01^{b}$ & $1.015 \pm 0.00^{\mathrm{b}}$ & $55.89 \pm 0.00^{\mathrm{b}}$ & $55.89 \pm 0.00^{\mathrm{b}}$ & $0.48 \pm 0.00^{\mathrm{a}}$ & $4.47 \pm 0.15^{\mathrm{a}}$ & $0.19 \pm 0.00^{\mathrm{a}}$ \\
\hline
\end{tabular}

Data are the means \pm standard deviation. Data with different superscript letters $(\mathrm{a}, \mathrm{b}, \mathrm{c}, \mathrm{d})$ within each column and each non-conventional species compared to $S$. cerevisiae US05 are significantly different (Duncan tests; $p<0.05$ ). 

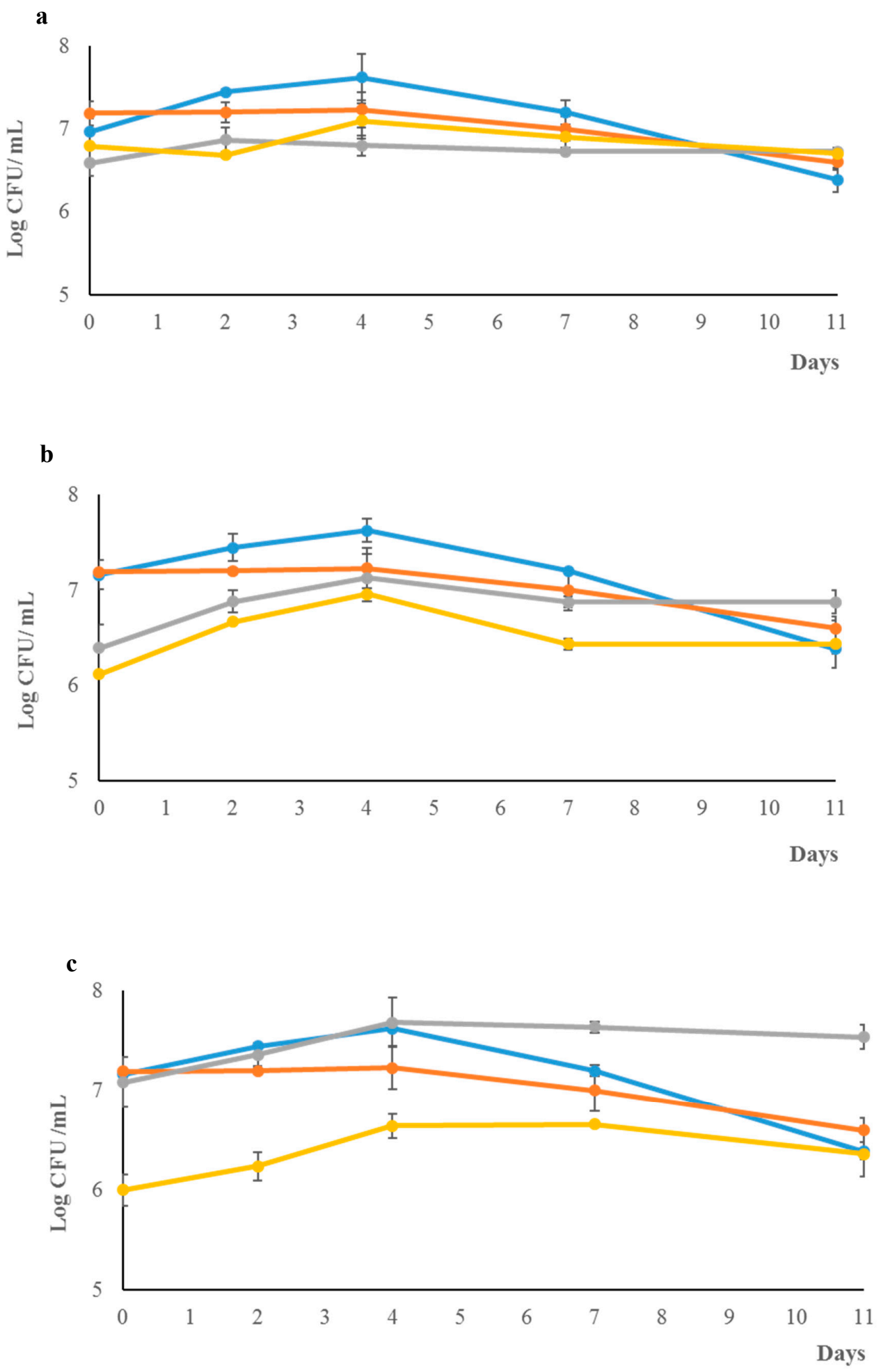

Figure 2. Growth kinetics of Z. florentina in pure and mixed fermentation. Pure cultures of Z. florentina $(\rightarrow)$ and S. cerevisiae $(-)$ ) and for the mixed fermentation with. S. cerevisiae $(-)$ and Z. florentina $(-)$ individually in the mixed cultures at 1:1 (a), 1:10 (b) and 1:20 (c).

At the 1:10 and 1:20 inoculation ratios (Figure 2a,b), the two yeast species did not show the antagonistic effect on each other, however, Z. florentina prevailed over S. cerevisiae during the fermentation processes. 
The cell evolution of $W$. anomalus in pure and mixed fermentations with $S$. cerevisiae showed the same trend exhibited by Z. florentina (Figure 3), indicating a good competition with S. cerevisiae in wort fermentation, especially when the inoculation level was 10- or 20-fold higher (1:10 and 1:20 trials). Despite the competition shown by the three non-conventional yeast species toward S. cerevisiae, all mixed fermentation trials (at different inoculation ratios) did not show relevant differences in the main analytical characteristics in comparison with the S. cerevisiae control trial (Table 2). Therefore, all the mixed fermentations have completed the fermentation as attested by the values of final gravity that are comparable with S. cerevisiae pure culture (Table 2).

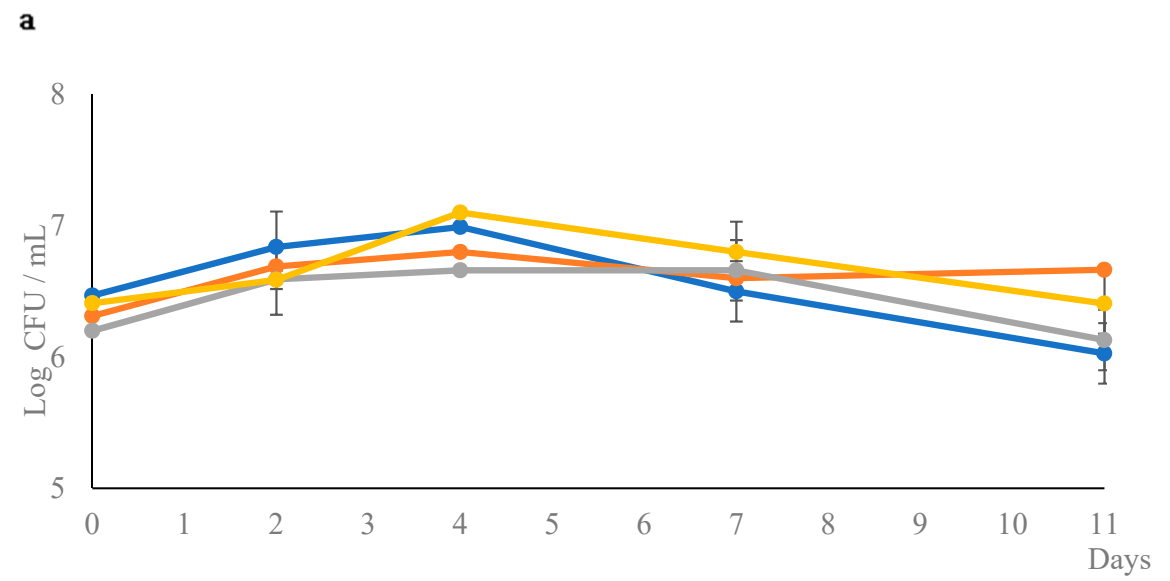

b

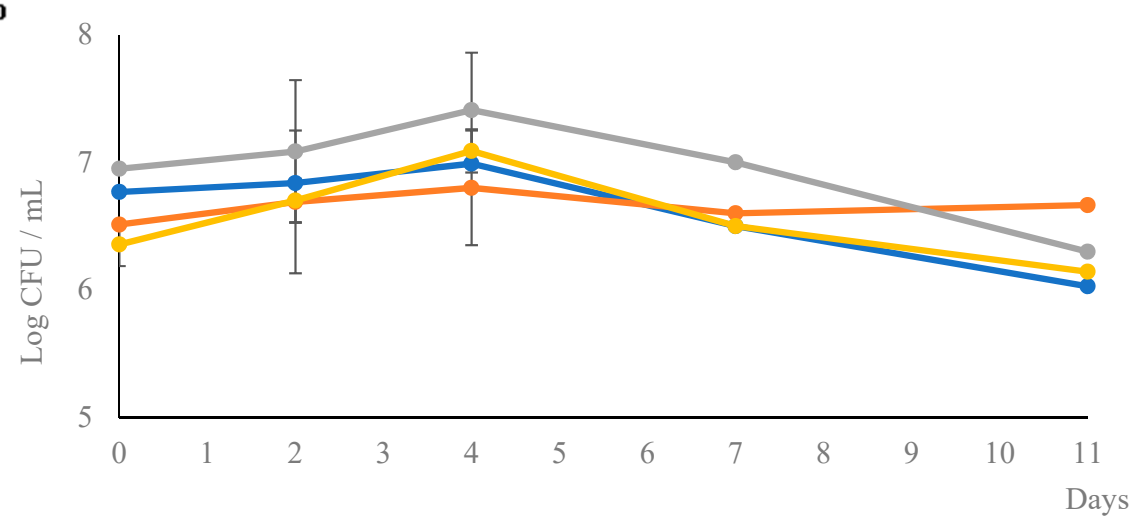

c

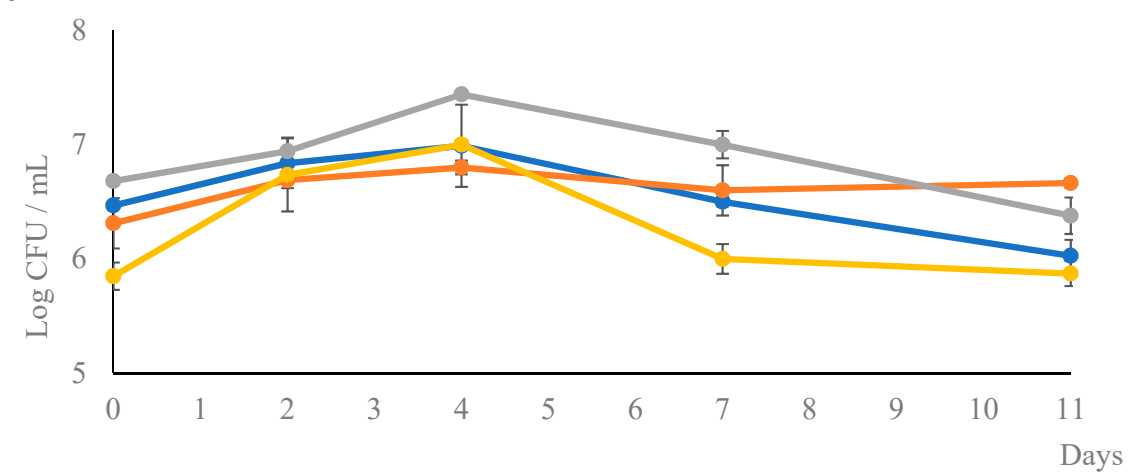

Figure 3. Growth kinetics of W. anomalus in pure and mixed fermentation. Pure cultures of W. anomalus $(-)$ and S. cerevisiae $(-)$ ) and for the mixed fermentation with S. cerevisiae $(-)$ and W. anomalus $(-)$ individually in the mixed cultures at 1:1 (a), 1:10 (b) and 1:20 (c). 


\subsubsection{Main Analytical Profiles}

The data regarding the analytical compositions of the beers produced are reported in Table 2.

The pure cultures with non-conventional yeasts showed significant reductions in ethanol content compared with the $S$. cerevisiae starter strain $(4.03 \% v / v)$. Indeed, beers produced by pure cultures of L. thermotolerans, Z. florentina, and W. anomalus exhibited an ethanol content of $3.12 \% v / v, 3.47 \%$ $v / v$, and $1.53 \% v / v$, respectively. Consequently, pure cultures of the non-conventional yeasts showed higher final gravities. On the other hand, all mixed cultures produced beers with an ethanol content not significantly different to that of the $S$. cerevisiae US- 05 control.

For the volatile acidity, the results did not show significant differences for the trials carried out with L. thermotolerans in comparison with S. cerevisiae pure culture, while Z. florentina at inoculation ratio 1:20 exhibited a significant increase in acetic acid content in comparison with $S$. cerevisiae and the other trials. Regarding W. anomalus significant increase was exhibited in pure and at inoculation ratio 1:20.

All of the beers exhibited $\mathrm{pH}$ values comparable to that of the $S$. cerevisiae starter strain, with the only exception being $L$. thermotolerans in pure and mixed fermentations. In particular, L. thermotolerans in pure culture exhibited a $\mathrm{pH}$ reduction of ca. 0.6 points. Regarding the lactic acid content, L. thermotolerans in pure and at different inoculum ratio exhibited a significantly higher concentration in comparison with the S. cerevisiae and the other two non-conventional yeasts. On the other hand, $W$. anomalus and $Z$. florentina in pure cultures exhibited lactic acid amounts significantly higher than those shown by the $S$. cerevisiae. Moreover, Z. florentina also at inoculation ratio 1:1 and 1:20 (S. cerevisiae/Z. florentina) exhibited a significant increase in comparison with S. cerevisiae, while at 1:10 ratio showed a comparable amount of lactic acid of $S$. cerevisiae. All mixed fermentation carried out with $W$. anomalus significantly increased the lactic acid content in comparison with S. cerevisiae.

\subsubsection{Main Volatile Compounds}

The main volatile compounds produced by L. thermotolerans in pure and mixed fermentations are reported in Table 3. The results highlighted a significant increase in ethyl acetate (fruit notes) content in pure and mixed fermentations compared with S. cerevisiae. L. thermotolerans in pure and mixed fermentations showed a significant increase in ethyl butyrate content, which is the ester responsible for the fruity or solvent aroma of beer [21], compared with S. cerevisiae US-05. A significant increase in isoamyl acetate content (banana aroma) was exhibited by L. thermotolerans at the 1:20 S. cerevisiae: $L$. thermotolerans inoculation ratio compared with $S$. cerevisiae in pure culture, while the concentration of ethyl hexanoate (i.e., apple, fruit flavour) decreased with increasing the inoculation ratios. The same trend was also exhibited for the linalool content. Furthermore, the citronellol content decreased in mixed fermentation at the 1:10 and 1:20 inoculation ratios, while at the 1:1 its concentration was comparable with that exhibited by the $S$. cerevisiae starter strain. Moreover, the mixed cultures showed significant increases in higher alcohols levels with the exception of $\beta$-phenyl ethanol. In regard to the acetaldehyde content, the mixed fermentations at the 1:1 inoculation ratio exhibited a reduction compared with the other beers.

In mixed fermentation trials, Z. florentina showed a significant decrease in acetaldehyde content compared with the beer obtained with the $S$. cerevisiae starter strain (Table 4).

Regarding the ester compounds, Table 4 showed a significant increase in ethyl butyrate content at 1:20 inoculation ratio in comparison with the other trials, while ethyl acetate increases in all mixed fermentation, phenyl ethyl acetate, ethyl hexanoate, and isoamyl acetate decreases when raising the inoculation ratio. Moreover, the mixed fermentations showed a significant increase in some higher alcohols content, with the only exception of $\beta$-phenyl ethanol that decreased in mixed fermentation in comparison with $S$. cerevisiae pure culture. Regarding terpens compounds, no significant differences were exhibited for $\alpha$-terpineol, while citronellol content significant decrease in mixed fermentation in comparison with S. cerevisiae pure culture. 
Table 3. The main by-products and volatile compounds in the beers produced by L. thermotolerans in the pure and mixed fermentations $(\mathrm{mg} / \mathrm{L})$.

\begin{tabular}{|c|c|c|c|c|c|}
\hline & $\begin{array}{c}\text { L. thermotolerans } \\
\text { DiSVA } 322\end{array}$ & $\begin{array}{c}\text { US05 + DiSVA } \\
322 \text { 1:1 }\end{array}$ & $\begin{array}{c}\text { US05 + DiSVA } \\
322 \text { 1:10 }\end{array}$ & $\begin{array}{c}\text { US05 + DiSVA } \\
322 \text { 1:20 }\end{array}$ & $\begin{array}{l}\text { S. cerevisiae } \\
\text { US- } 05\end{array}$ \\
\hline \multicolumn{6}{|l|}{ Esters } \\
\hline Ethyl butyrate & $0.32 \pm 0.01^{\mathrm{a}}$ & $0.20 \pm 0.13^{\mathrm{ab}}$ & $0.14 \pm 0.03 \mathrm{bc}$ & $0.14 \pm 0.03^{b c}$ & $0.04 \pm 0.01^{c}$ \\
\hline Ethyl acetate & $17.4 \pm 4.6^{\mathrm{bc}}$ & $21.3 \pm 0.6^{\mathrm{a}}$ & $17.0 \pm 4.4 \mathrm{bc}$ & $24.6 \pm 6.7^{\mathrm{a}}$ & $2.6 \pm 0.2^{c}$ \\
\hline Phenyl ethyl acetate & $0.01 \pm 0.01^{c}$ & $0.09 \pm 0.02^{b}$ & $0.08 \pm 0.01^{b}$ & $0.08 \pm 0.02^{b}$ & $0.45 \pm 0.01^{\mathrm{a}}$ \\
\hline Ethyl hexanoate & $0.00 \pm 0.00^{c}$ & $0.19 \pm 0.01^{\mathrm{a}}$ & $0.13 \pm 0.03^{b}$ & $0.06 \pm 0.01^{c}$ & $0.22 \pm 0.03^{\mathrm{a}}$ \\
\hline Isoamyl acetate & $0.10 \pm 0.00^{\mathrm{d}}$ & $0.15 \pm 0.00^{\mathrm{c}}$ & $0.20 \pm 0.01^{b}$ & $0.29 \pm 0.01^{\mathrm{a}}$ & $0.19 \pm 0.01^{\mathrm{b}}$ \\
\hline \multicolumn{6}{|l|}{ Alcohols } \\
\hline n-Propanol & $14.1 \pm 0.3^{\mathrm{d}}$ & $24.9 \pm 0.8^{\mathrm{ab}}$ & $26.5 \pm 0.3^{\mathrm{a}}$ & $22.6 \pm 2.4^{b}$ & $17.8 \pm 0.3^{c}$ \\
\hline Isobutanol & $6.6 \pm 0.2^{\mathrm{d}}$ & $18.0 \pm 0.9 \mathrm{ab}$ & $19.2 \pm 0.7^{\mathrm{a}}$ & $16.4 \pm 1.5^{b}$ & $9.5 \pm 0.3^{c}$ \\
\hline Amylic alcohol & $4.1 \pm 0.1^{\mathrm{d}}$ & $14.0 \pm 0.03^{\mathrm{a}}$ & $12.7 \pm 0.2^{b}$ & $12.3 \pm 0.1^{b}$ & $7.9 \pm 0.2^{c}$ \\
\hline Isoamylic alcohol & $30.2 \pm 0.2^{\mathrm{d}}$ & $56.1 \pm 1.4^{b}$ & $61.9 \pm 0.9^{\mathrm{a}}$ & $56.3 \pm 2.5^{b}$ & $37.23 \pm 1.8^{c}$ \\
\hline$\beta$-Phenyl ethanol & $4.53 \pm 0.03^{c}$ & $6.44 \pm 0.01^{b}$ & $6.16 \pm 0.01^{b}$ & $4.25 \pm 0.00^{c}$ & $7.29 \pm 0.00^{\mathrm{a}}$ \\
\hline \multicolumn{6}{|l|}{ Carbonyl compounds } \\
\hline Acetaldehyde & $82.4 \pm 6.8^{b}$ & $38.5 \pm 2.8^{c}$ & $102.6 \pm 8.7^{\mathrm{a}}$ & $93.0 \pm 3.7^{\mathrm{ab}}$ & $84.9 \pm 7.03^{b}$ \\
\hline \multicolumn{6}{|l|}{ Terpens } \\
\hline Linalool & $0.09 \pm 0.01^{\mathrm{ab}}$ & $0.11 \pm 0.02^{\mathrm{a}}$ & $0.07 \pm 0.01^{b c}$ & $0.05 \pm 0.01^{\mathrm{c}}$ & $0.11 \pm 0.01^{\mathrm{a}}$ \\
\hline$\alpha$-terpineol & $0.045 \pm 0.002^{b c}$ & $0.034 \pm 0.00^{c}$ & $0.134 \pm 0.276^{\mathrm{a}}$ & $0.042 \pm 0.014^{b c}$ & $0.058 \pm 0.001^{b}$ \\
\hline Citronellol & $0.210 \pm 0.01^{\mathrm{e}}$ & $0.747 \pm 0.007^{b}$ & $0.612 \pm 0.007^{c}$ & $0.436 \pm 0.00^{\mathrm{d}}$ & $0.781 \pm 0.014^{\mathrm{a}}$ \\
\hline
\end{tabular}

Data are the means \pm standard deviation. Data with different superscript letters $\left({ }^{\mathrm{a}, \mathrm{b}, \mathrm{c}, \mathrm{d}}\right)$ within each row are significantly different (Duncan tests; $p<0.05$ ).

Table 4. The main by-products and volatile compounds in the beers produced by Z. florentina in the pure and mixed fermentations $(\mathrm{mg} / \mathrm{L})$.

\begin{tabular}{|c|c|c|c|c|c|}
\hline & $\begin{array}{l}\text { Z. florentina DiSVA } \\
263\end{array}$ & $\begin{array}{c}\text { US05 + DiSVA } \\
263 \text { 1:1 }\end{array}$ & $\begin{array}{c}\text { US05 + DiSVA } \\
2631: 10\end{array}$ & $\begin{array}{c}\text { US05 + DiSVA } \\
2631: 20\end{array}$ & $\begin{array}{l}\text { S. cerevisiae } \\
\text { US-05 }\end{array}$ \\
\hline \multicolumn{6}{|l|}{ Esters } \\
\hline Ethyl butyrate & $0.02 \pm 0.014^{\mathrm{c}}$ & $0.01 \pm 0.00^{c}$ & $0.064 \pm 0.014^{b}$ & $0.140 \pm 0.014^{\mathrm{a}}$ & $0.042 \pm 0.014^{b}$ \\
\hline Ethyl acetate & $1.6 \pm 0.1^{b}$ & $8.33 \pm 0.04^{\mathrm{a}}$ & $7.7 \pm 2.1^{\mathrm{a}}$ & $6.7 \pm 5.0^{\mathrm{a}}$ & $2.6 \pm 0.2^{b}$ \\
\hline Phenyl ethyl acetate & $0.17 \pm 0.017^{\mathrm{d}}$ & $0.317 \pm 0.01^{b}$ & $0.26 \pm 0.0^{c}$ & $0,09 \pm 0.02^{b}$ & $0.45 \pm 0.01^{\mathrm{a}}$ \\
\hline Ethyl hexanoate & $0.00 \pm 0.00^{c}$ & $0.09 \pm 0.02^{b}$ & $0.08 \pm 0.00^{b}$ & $0.02 \pm 0.00^{c}$ & $0.22 \pm 0.03^{\mathrm{a}}$ \\
\hline Isoamyl acetate & $0.30 \pm 0.01^{\mathrm{a}}$ & $0.34 \pm 0.02^{\mathrm{a}}$ & $0.23 \pm 0.01^{b}$ & $0.33 \pm 0.04^{\mathrm{a}}$ & $0.190 \pm 0.01^{b}$ \\
\hline \multicolumn{6}{|l|}{ Alcohols } \\
\hline n-Propanol & $14.0 \pm 3.0^{\mathrm{b}}$ & $19.44 \pm 0.36^{\mathrm{a}}$ & $18.9 \pm 1.9^{a}$ & $19.9 \pm 0.3^{a}$ & $17.8 \pm 0.3^{c}$ \\
\hline Isobutanol & $6.9 \pm 3.1^{b}$ & $11.25 \pm 1.34^{\mathrm{a}}$ & $10.2 \pm 0.3^{\mathrm{ab}}$ & $11.8 \pm 0.3^{\mathrm{a}}$ & $9.5 \pm 0.3^{a b}$ \\
\hline Amylic alcohol & $3.49 \pm 2.7^{b}$ & $7.85 \pm 0.17^{\mathrm{a}}$ & $7.9 \pm 0.7^{\mathrm{a}}$ & $7.8 \pm 1.0^{\mathrm{a}}$ & $7.9 \pm 0.2^{\mathrm{a}}$ \\
\hline Isoamylic alcohol & $20.4 \pm 13.4^{\mathrm{c}}$ & $43.53 \pm 3.21^{\mathrm{a}}$ & $41.0 \pm 1.6^{\mathrm{a}}$ & $41.3 \pm 0.3^{\mathrm{a}}$ & $37.23 \pm 1.8^{b c}$ \\
\hline$\beta$-Phenyl ethanol & $1.74 \pm 0.144^{\mathrm{e}}$ & $3.94 \pm 0.001^{c}$ & $4.17 \pm 0.007^{b}$ & $2.78 \pm 0.001^{\mathrm{d}}$ & $7.29 \pm 0.00^{a}$ \\
\hline \multicolumn{6}{|l|}{ Carbonyl compounds } \\
\hline Acetaldehyde & $14.2 \pm 1.9^{\mathrm{d}}$ & $51.63 \pm 9.74^{c}$ & $56.9 \pm 0.9^{b c}$ & $68.8 \pm 0.014^{\mathrm{b}}$ & $84.9 \pm 7.03^{a}$ \\
\hline \multicolumn{6}{|l|}{ Terpens } \\
\hline Linalol & $0.051 \pm 0.014^{b}$ & $0.124 \pm 0.028^{a}$ & $0.129 \pm 0.007^{\mathrm{a}}$ & $0.041 \pm 0.001^{b}$ & $0.114 \pm 0.007^{\mathrm{a}}$ \\
\hline$\alpha$-terpineol & $0.094 \pm 0.028^{\mathrm{a}}$ & $0.078 \pm 0.006^{\mathrm{a}}$ & $0.088 \pm 0.001^{\mathrm{a}}$ & $0.077 \pm 0.015^{\mathrm{a}}$ & $0.058 \pm 0.001^{\mathrm{a}}$ \\
\hline Citronellol & $0.401 \pm 0.020^{c}$ & $0.402 \pm 0.073^{c}$ & $0.263 \pm 0.022^{b}$ & $0.237 \pm 0.026^{\mathrm{d}}$ & $0.781 \pm 0.014^{\mathrm{a}}$ \\
\hline
\end{tabular}

Data are the means \pm standard deviation. Data with different superscript letters $(\mathrm{a}, \mathrm{b}, \mathrm{c}, \mathrm{d})$ within each row are significantly different (Duncan tests; $p<0.05$ ).

The use of $W$. anomalus (Table 5) in mixed fermentation led to a reduction in acetaldehyde and an increase in ethyl acetate in comparison with the beers obtained with S. cerevisiae. In pure fermentation, $W$. anomalus showed a significant increase of higher alcohols (n-propanol, isobutanol, amylic and isoamylic alcohol). On the other hand, W. anomalus in mixed fermentations showed higher alcohols concentrations comparable to those exhibited by S. cerevisiae. W. anomalus in mixed fermentations increased the ethyl butyrate content, while ethyl hexanoate, phenyl ethyl acetate, and $\beta$-phenyl ethanol were decreased in comparison with S. cerevisiae pure culture. In contrast, the levels of linalool did not show significant differences in the final beers. Regarding $\alpha$-terpineol, this aroma compound 
significantly increased in mixed fermentation at the 1:1 inoculation ratio. The citronellol content decreased in mixed fermentations with increasing of the inoculation ratio of W. anomalus.

Table 5. The main by-products and volatile compounds in the beers produced by W. anomalus in the pure and mixed fermentations $(\mathrm{mg} / \mathrm{L})$.

\begin{tabular}{|c|c|c|c|c|c|}
\hline & $\begin{array}{l}\text { W. anomalus } \\
\text { DiSVA } 2\end{array}$ & $\begin{array}{c}\text { US05 + DiSVA } \\
21: 1\end{array}$ & $\begin{array}{c}\text { US05 + DiSVA } \\
21: 10\end{array}$ & $\begin{array}{c}\text { US05 + DiSVA } \\
2 \text { 1:20 }\end{array}$ & $\begin{array}{l}\text { S. cerevisiae } \\
\text { US-05 }\end{array}$ \\
\hline \multicolumn{6}{|l|}{ Esters } \\
\hline Ethyl butyrate & $0.040 \pm 0.042^{c}$ & $0.292 \pm 0.021^{\mathrm{a}}$ & $0.216 \pm 0.008^{b}$ & $0.218 \pm 0.007^{b}$ & $0.042 \pm 0.014^{\mathrm{c}}$ \\
\hline Ethyl acetate & $1.7 \pm 0.7^{c}$ & $15.7 \pm 2.5^{\mathrm{a}}$ & $9.6 \pm 1.9^{b}$ & $7.5 \pm 0.9^{b}$ & $2.6 \pm 0.2^{c}$ \\
\hline Phenyl ethyl acetate & $0.061 \pm 0.035^{\mathrm{d}}$ & $0.153 \pm 0.001^{\mathrm{cd}}$ & $0.360 \pm 0.007^{b}$ & $0.230 \pm 0.070^{c}$ & $0.452 \pm 0.01^{\mathrm{a}}$ \\
\hline Ethyl hexanoate & $0.056 \pm 0.014^{c}$ & $0.115 \pm 0.007^{b}$ & $0.058 \pm 0.014^{\mathrm{c}}$ & $0.098 \pm 0.001^{b}$ & $0.225 \pm 0.029^{a}$ \\
\hline Isoamyl acetate & $0.051 \pm 0.049^{c}$ & $0.186 \pm 0.021^{b}$ & $0.572 \pm 0.735^{\mathrm{a}}$ & $0.273 \pm 0.004^{b}$ & $0.190 \pm 0.014^{b}$ \\
\hline \multicolumn{6}{|l|}{ Alcohols } \\
\hline n-Propanol & $22.5 \pm 0.9^{a}$ & $17.9 \pm 0.7^{c}$ & $19.8 \pm 0.5^{b}$ & $17.4 \pm 0.5^{\mathrm{c}}$ & $17.8 \pm 0.3^{c}$ \\
\hline Isobutanol & $10.8 \pm 1.3^{\mathrm{a}}$ & $7.6 \pm 2.7^{b}$ & $8.7 \pm 0.6^{b}$ & $8.4 \pm 0.3^{b}$ & $9.5 \pm 0.3^{b}$ \\
\hline Amylic alcohol & $9.2 \pm 0.5^{\mathrm{a}}$ & $7.8 \pm 1.4^{\mathrm{a}}$ & $7.2 \pm 0.1^{\mathrm{a}}$ & $7.2 \pm 1.8^{\mathrm{a}}$ & $7.9 \pm 0.2^{c}$ \\
\hline Isoamylic alcohol & $51.6 \pm 4.1^{\mathrm{a}}$ & $35.0 \pm 4.8^{b}$ & $38.4 \pm 6.8^{b}$ & $32.0 \pm 8.2^{b}$ & $37.23 \pm 1.8^{b}$ \\
\hline$\beta$-Phenyl ethanol & $0.00 \pm 0.00^{\mathrm{e}}$ & $4.70 \pm 0.020^{c}$ & $6.14 \pm 0.030^{b}$ & $3.50 \pm 0.008^{d}$ & $7.29 \pm 0.00^{\mathrm{a}}$ \\
\hline \multicolumn{6}{|l|}{ Carbonyl compounds } \\
\hline Acetaldehyde & $49.3 \pm 2.8^{c}$ & $57.0 \pm 2.2^{b}$ & $51.00 \pm 0.02^{c}$ & $26.8 \pm 2.5^{\mathrm{d}}$ & $84.9 \pm 7.03^{a}$ \\
\hline \multicolumn{6}{|l|}{ Terpens } \\
\hline Linalol & $0.110 \pm 0.010^{a}$ & $0.181 \pm 0.039^{a}$ & $0.190 \pm 0.029^{a}$ & $0.163 \pm 0.006^{\mathrm{a}}$ & $0.114 \pm 0.007^{\mathrm{a}}$ \\
\hline$\alpha$-terpineol & $0.022 \pm 0.001^{c}$ & $0.130 \pm 0.014^{\mathrm{a}}$ & $0.062 \pm 0.018^{b}$ & $0.088 \pm 0.032^{b}$ & $0.058 \pm 0.001^{b}$ \\
\hline Citronellol & $0.00 \pm 0.00^{c}$ & $0.00 \pm 0.00^{c}$ & $0.155 \pm 0.032^{b}$ & $0.165 \pm 0.042^{b}$ & $0.781 \pm 0.014^{\mathrm{a}}$ \\
\hline
\end{tabular}

Data are the means \pm standard deviation. Data with different superscript letters $\left({ }^{\mathrm{a}, \mathrm{b}, \mathrm{c}, \mathrm{d}}\right)$ within each row are significantly different (Duncan tests; $p<0.05$ ).

To assess the overall effects of non-conventional yeasts in pure and mixed fermentation, data regarding all of the volatile compounds were analysed by PCA (Figure 4). The PCA analysis showed that $Z$. florentina in pure and mixed fermentation fell into the left half of sample distribution together with $L$. thermotolerans and $W$. anomalus pure cultures. Moreover, $W$. anomalus and L. thermotolerans mixed fermentations are located in the upper right, and in the right of the representation respectively. These results highlighted that each non-conventional yeast species affect the final volatile profile in a different way.

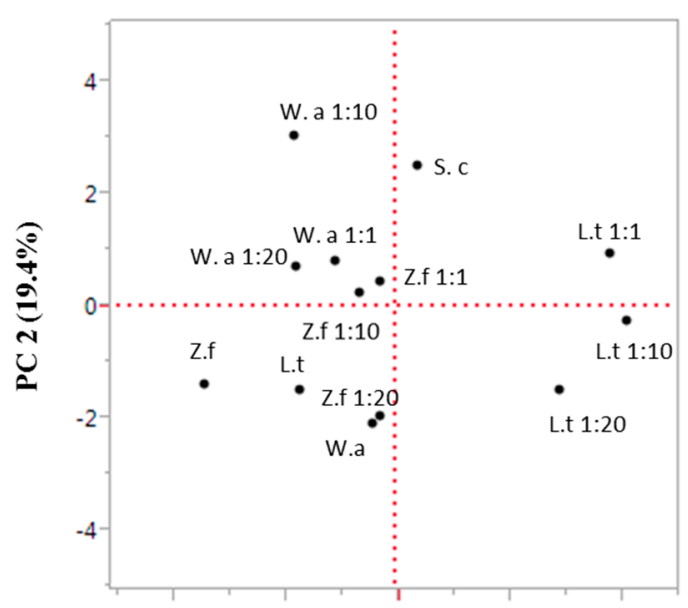

PC $1(37.7 \%)$

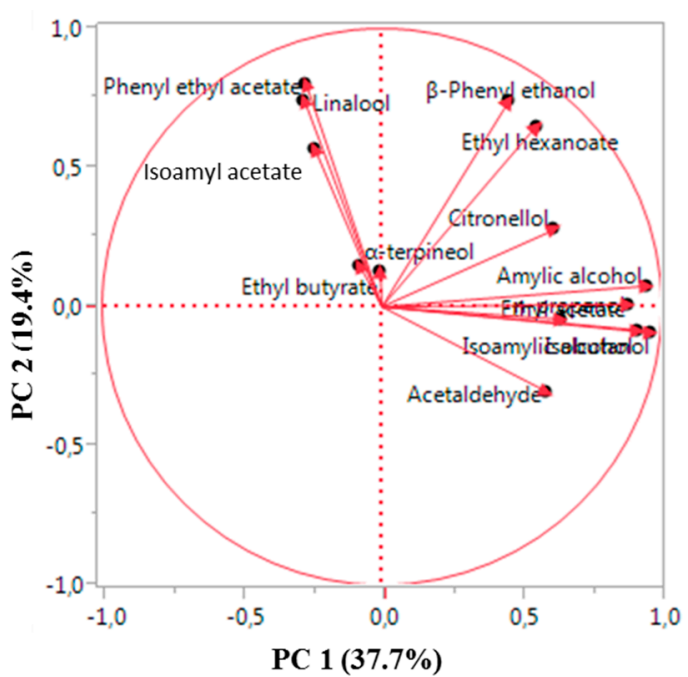

PC $1(37.7 \%)$

Figure 4. Principal component analysis for the main by-products and volatile compounds of the pure non-conventional yeasts (L. $\mathrm{t}=$ L. thermotolerans; $\mathrm{W} . \mathrm{a}=\mathrm{W}$. anomalus; $\mathrm{Z} . \mathrm{f}=\mathrm{Z}$. florentina) and their mixed fermentations with $S$. cerevisiae (S. c). The variance explained by principle component analysis (PCA) analysis is PC $137.7 \%$ X-axis and PC 2 19.4\% Y-axis). PC 1: principal component. 


\section{Discussion}

In winemaking, the controlled use of non-conventional yeast species has been investigated to enhance complexity and give distinctive flavour profiles of wines [22-24].

Indeed, fermented alcoholic beverages with peculiar and distinctive flavours can be obtained through the yeast inoculation during the fermentation process $[11,21,25]$. In this regard, the potential use of non-conventional yeasts in brewing has been poorly explored. Only recently, some studies focused on flavouring by non-conventional yeasts in brewing $[7,9,14,16,26]$.

In this work, we investigated three non-conventional yeast species widely found in the wine environment $[23,27,28]$. The three strains chosen within the three species were competitive versus the S. cerevisiae starter strain at the 1:1 inoculation ratio exhibiting similar numbers of viable cells. The competition of the non-conventional species in wort under semi-anaerobic conditions was confirmed for the 1:10 and 1:20 ratios (S. cerevisiae brewers' yeast: Non-conventional species). In these last conditions, all three non-conventional yeast species coexisted with brewers' yeast dominating the fermentation process. Similar results were found by Van Rijswijck et al. [17] where Candida fabianii at a 1:100 ratios (S. cerevisiae: C. fabianii) dominated the fermentation. However, compared to the results of the present work, a large amount of residual maltose was found.

This behaviour is of interest from a practical application point of view. Indeed, the dominance allows displaying the metabolism of the non-conventional yeast in co-culture with the brewing starter, obtaining, at the same time, a distinctive aromatic impact on final product and a correct and complete evolution of the fermentation. In this regard, differences in the analytical composition using the three non-conventional yeasts in pure and in co-culture were found (see Figure 4). All three non-conventional species determined a general decrease of acetaldehyde in all mixed fermentations (1:1, 1:10, 1:20 S. cerevisiae/non-conventional yeasts ratios).

L. thermotolerans, a yeast species widely investigated in wine fermentation, [28,29] showed a large reduction in $\mathrm{pH}$ compared with the S. cerevisiae starter strain. Domizio et al. [15] and Osburn et al. [8], investigating $L$. thermotolerans in pure fermentation with the goal of producing sour beer, and found a compared trend in $\mathrm{pH}$ reduction. In the wort used in this work, L. thermotolerans in pure culture produced a larger amount of lactic acid $(1.83 \mathrm{~g} / \mathrm{L})$ compared with the quantities shown in the study of Domizio et al. [15] (0.24 g/L). Regarding the compounds influencing the bioflavor, L. thermotolerans produced beer with a higher ethyl butyrate content and an increase in ethyl acetate (i.e., floral, honey, sweet) in pure and in all of the mixed fermentations compared with S. cerevisiae. Moreover, a significant increase in isoamyl acetate content (banana aroma) was exhibited in the trial S. cerevisiae/ $L$. thermotolerans at an inoculum ratio of 1:20. These results highlighted that this strain was interesting not only for sour beer production due to its lactic acid production and consequent $\mathrm{pH}$ decrease during primary fermentation but also to tailor the aroma profile of the beer. The low ethanol content exhibited by L. thermotolerans pure cultures was also relevant for the production of low alcohol beer. W. anomalus generally studied in apple wine and hard cider production [30,31], it was poorly investigated in brewing because it is associated with the concept of "spoilage yeast" [32]. Only Osburn at al. [8] showed that a strain of $W$. anomalus exhibited a good fermentation performance and led beers with fruit notes such as apple, pear, and apricot. Results of this study showed an increase in ethyl butyrate and ethyl acetate and a reduction in acetaldehyde in all mixed fermentations that positively affect the aromatic profile of the beer. As reported above, there are no studies on the use of this species in beer, thus, for this reason, it is difficult to understand the general behaviour of this non-conventional yeast in the brewing process and further investigations are needed. Furthermore, there is only one study that evaluated the use of the non-conventional yeast $Z$. florentina in brewing. In contrast to the report of Holt et al. [16] that showed increases in higher alcohols, we observed a different trend for these compounds. On the other hand, Z. florentina showed increased isoamyl acetate and $\alpha$-terpineol content (floreal aroma) that positively influenced the final flavour of the beer. In conclusion, the use of non-conventional yeasts in mixed fermentations with S. cerevisiae is a suitable strategy to tailor flavour production during beer fermentation, thus making it possible to obtain products with aroma 
compounds that are different from those of beers brewed using pure S. cerevisiae starter strains. These data confirm that the brewing yeast used can modulate the production of the aroma compounds in the final beers. The modalities (pure or co-cultures with S. cerevisiae) and the inoculation ratio in mixed fermentations should be further investigated, even if the non-conventional yeasts coexist, and in some cases, dominate the process, the fermentations are almost completed. In this regard, further work is needed to understand the behaviours of these non-conventional yeasts in the brewing process and to know their possible uses in different beer styles. The next necessary step will be evaluating the selected combination of $S$. cerevisiae/non-conventional yeasts on a large scale to evaluate through sensory analysis the beer style more suitable for these yeasts.

Author Contributions: L.C., E.G., E.C., M.C. and F.C. contributed equally to this manuscript. All authors participated in the design and discussion of the research. L.C., E.G. and E.C. carried out the experimental part of the work. L.C., E.G., M.C. and F.C. carried out the analysis of the data and wrote the manuscript. All authors have read and approved the final manuscript.

Funding: This research was funded by Università Politecnica delle Marche, Ricerca Scientifica di Ateneo RSA2016, n. $0025307 / 2016$.

Acknowledgments: L. Canonico was supported by Polytechnic University of Marche Postdoctoral contract (D.R. n^1057 del 20.10.2016). The authors wish to thank the Birra dell'Eremo Microbrewery (Assisi, Italy) for providing the facilities and the wort for the trials.

Conflicts of Interest: The authors declare that they have no conflict of interest.

\section{References}

1. Saerens, S.M.G.; Duong, C.T.; Nevoigt, E. Genetic improvement of brewer's yeast: Current state, perspectives and limits. Appl. Microbiol. Biotechnol. 2010, 86, 1195-1212. [CrossRef]

2. Steensels, J.; Snoeka, T.; Meersmana, E.; Nicolino, M.P.; Aslankoohi, E.; Christiaens, J.F.; Gemayel, R.; Meert, W.; Newa, A.M.; Pougacha, K.; et al. Selecting and generating superior yeasts for the brewing industry. Cerevisia 2012, 37, 63-67. [CrossRef]

3. Steensels, J.; Verstrepen, K. Taming wild yeast: Potential of conventional and non-conventional yeasts in industrial fermentations. Annu. Rev. Microbiol. 2014, 68, 61-80. [CrossRef]

4. Marongiu, A.; Zara, G.; Legras, J.L.; Del Caro, A.; Mascia, I.; Fadda, C.; Budroni, M. Novel starters for old processes: Use of Saccharomyces cerevisiae strains isolated from artisanal sourdough for craft beer production at a brewery scale. J. Ind. Microbiol. Biotechnol. 2015, 42, 85-92. [CrossRef]

5. Mascia, I.; Fadda, C.; Dostálek, P.; Karabín, M.; Zara, G.; Budroni, M.; Del Caro, A. Is it possible to create an innovative craft durum wheat beer with sourdough yeasts? A case study. J. Inst. Brew. 2015, 121, $283-286$. [CrossRef]

6. Canonico, L.; Comitini, F.; Ciani, M. Dominance and influence of selected Saccharomyces cerevisiae strains on the analytical profile of craft beer refermentation. J. Inst. Brew. 2014, 120, 262-267. [CrossRef]

7. Canonico, L.; Agarbati, A.; Comitini, F.; Ciani, M. Torulaspora delbrueckii in the brewing process: A new approach to enhance bioflavour and to reduce ethanol content. Food Microbiol. 2016, 56, 45-51. [CrossRef]

8. Osburn, K.; Amaral, J.; Metcalf, S.R.; Nickens, D.M.; Rogers, C.M.; Sausen, C.; Caputo, R.; Miller, J.; Li, H.; Tennessen, J.M.; et al. Primary souring: A novel bacteria-free method for sour beer production. Food Microbiol. 2018, 70, 76-84. [CrossRef]

9. Van Rijswijck, I.M.; Wolkers-Rooijackers, J.; Abee, T.; Smid, E.J. Performance of non-conventional yeasts in co culture with brewers' yeast for steering ethanol and aroma production. Microb. Biotechnol. 2017, 10, 1591-1602. [CrossRef]

10. Toh, D.W.K.; Chua, J.Y.; Liu, S.Q. Impact of simultaneous fermentation with Saccharomyces cerevisiae and Torulaspora delbrueckii on volatile and non-volatile constituents in beer. LWT 2018, 91, 26-33. [CrossRef]

11. Carlquist, M.; Gibson, B.; Karagul Yuceer, Y.; Paraskevopoulou, A.; Sandell, M.; Angelov, A.I.; Gotcheva, V.; Angelov, A.D.; Etschmann, M.; de Billerbeck, G.M.; et al. Process engineering for bioflavour production with metabolically active yeasts-A mini-review. Yeast. 2015, 32, 123-143. [CrossRef]

12. Vanderhaegen, B.; Neven, H.; Coghe, S.; Verstrepen, K.J.; Derdelinckx, G.; Verachtert, H. Bioflavoring and beer refermentation. Appl. Microbiol. Biotechnol. 2003, 62, 140-150. [CrossRef] 
13. Canonico, L.; Comitini, F.; Ciani, M. Torulaspora delbrueckii contribution in mixed brewing fermentations with different Saccharomyces cerevisiae strains. Int. J. Food Microbiol. 2017, 259, 7-13. [CrossRef]

14. Michel, M.; Kopecká, J.; Meier-Dörnberg, T.; Zarnkow, M.; Jacob, F.; Hutzler, M. Screening for new brewing yeasts in the non-Saccharomyces sector with Torulaspora delbrueckii as model. Yeast 2016, 33, 129-144. [CrossRef]

15. Domizio, P.; House, J.F.; Joseph, C.M.L.; Bisson, L.F.; Bamforth, C.W. Lachancea thermotolerans as an alternative yeast for the production of beer. J. Inst. Brew. 2016, 122, 599-604. [CrossRef]

16. Holt, S.; Mukherjee, V.; Lievens, B.; Verstrepen, K.J.; Thevelein, J.M. Bioflavoring by non-conventional yeasts in sequential beer fermentations. Food Microbiol. 2018, 72, 55-66. [CrossRef]

17. Van Rijswijck, I.M.; Derks, M.F.; Abee, T.; de Ridder, D.; Smid, E.J. Genome sequences of Cyberlindnera fabianii 65, Pichia kudriavzevii 129, and Saccharomyces cerevisiae 131 isolated from fermented masau fruits in Zimbabwe. Genome Announc. 2017, 5, e00064-17. [CrossRef]

18. EC. Community Reference Methods for the Analysis of Spirit Drinks; Reg. EC No. 2870/00; Official Journal of the European Communities: Brussels, Belgium, 2000.

19. Canonico, L.; Comitini, F.; Ciani, M. Influence of vintage and selected starter on Torulaspora delbrueckii/ Saccharomyces cerevisiae sequential fermentation. Eur. Food Res. Technol. 2015, 241, 827-833. [CrossRef]

20. Oro, L.; Feliziani, E.; Ciani, M.; Romanazzi, G.; Comitini, F. Volatile organic compounds from Wickerhamomyces anomalus, Metschnikowia pulcherrima and Saccharomyces cerevisiae inhibit growth of decay causing fungi and control postharvest diseases of strawberries. Int. J. Food Microbiol. 2018, 265, 18-22. [CrossRef]

21. Pires, E.J.; Teixeira, J.A.; Brányik, T.; Vincente, A.A. Yeast: The soul of beer's aroma and a review of flavour-active esters and higher alcohols produced by the brewing yeast. Appl. Microbiol. Biotechnol. 2014, 98, 1937-1949. [CrossRef]

22. Ciani, M.; Comitini, F. Yeast interactions in multi-starter wine fermentation. Curr. Opin. Food Sci. 2015, 1, 1-6. [CrossRef]

23. Jolly, N.P.; Varela, C.; Pretorius, I.S. Not your ordinary yeast: Non-Saccharomyces yeasts in wine production uncovered. FEMS Yeast Res. 2014, 14, 215-237. [CrossRef]

24. Varela, C. The impact of non-Saccharomyces yeasts in the production of alcoholic beverages. Appl. Microbiol. Biotechnol. 2016, 100, 9861-9874. [CrossRef]

25. Hughes, P. Beer flavor. In Beer: A Quality Perspective; Bamforth, C.W., Ed.; Elsevier: New York, NY, USA, 2009; pp. 61-83.

26. Petruzzi, L.; Carbo, M.; Sinigaglia, M.; Bevilacqua, A. Brewers' yeast in controlled and uncontrolled fermentation, with a focus on novel, non-conventional and superior strains. Food Rev. Int. 2016, 32, 341-363. [CrossRef]

27. Lencioni, L.; Romani, C.; Gobbi, M.; Comitini, F.; Ciani, M.; Domizio, P. Controlled mixed fermentation at winery scale using Zygotorulaspora florentina and Saccharomyces cerevisiae. Int. J. Food Microbiol. 2016, 234, 36-44. [CrossRef]

28. Gobbi, M.; Comitini, F.; Domizio, P.; Romani, C.; Lencioni, L.; Mannazzu, I.; Ciani, M. Lachancea thermotolerans and Saccharomyces cerevisiae in simultaneous and sequential co-fermentation: A strategy to enhance acidity and improve the overall quality of wine. Food Microbiol. 2013, 33, 271-281. [CrossRef]

29. Benito, A.; Calderon, F.; Palomero, F.; Benito, S. Quality and composition of Airén wines fermented by sequential inoculation of Lachancea thermotolerans and Saccharomyces cerevisiae. Food Technol. Biotechnol. 2016, 54, 135-144. [CrossRef]

30. Satora, P.; Tarko, T.; Sroka, P.; Blaszczyk, U. The influence of Wickerhamomyces anomalus killer yeast on the fermentation and chemical composition of apple wines. FEMS Yeast Res. 2014, 14, 729-740. [CrossRef]

31. Ye, M.; Yue, T.; Yuan, Y. Effects of sequential mixed cultures of Wickerhamomyces anomalus and Saccharomyces cerevisiae on apple cider fermentation. FEMS Yeast Res. 2014, 14, 873-882. [CrossRef]

32. Timke, M.; Wang-Lieu, N.Q.; Altendorf, K.; Lipski, A. Identity, beer spoiling and biofilm forming potential of yeasts from beer bottling plant associated biofilms. Antonie Leeuwenhoek 2008, 93, 151-161. [CrossRef]

(C) 2019 by the authors. Licensee MDPI, Basel, Switzerland. This article is an open access article distributed under the terms and conditions of the Creative Commons Attribution (CC BY) license (http:/ / creativecommons.org/licenses/by/4.0/). 